\title{
DIVULGANDO NUEVAS IDEAS SOBRE LA DIVERSIDAD HUMANA: LA DIMENSIÓN EDUCATIVA DEL DISCURSO SOBRE LA DISCAPACIDAD EN LA ESPAÑA FRANQUISTA
}

\author{
José Martínez-Pérez \\ Facultad de Medicina de Albacete \\ Universidad de Castilla-La Mancha \\ Jose.MPerez@uclm.es \\ ORCID iD: https://orcid.org/0000-0001-8042-6244 \\ Mercedes Del Cura \\ Facultad de Medicina de Albacete. \\ Universidad de Castilla-La Mancha \\ Mercedes.DelCura@ulcm.es \\ ORCID iD: https://orcid.org/0000-0002-5972-7293
}

Recibido: 26 abril 2018; Aprobado: 22 enero 2019.

Cómo citar este artículo/Citation: Martínez-Pérez, José / Del Cura, Mercedes (2019), "Divulgando nuevas ideas sobre la diversidad humana: la dimensión educativa del discurso sobre la discapacidad en la España franquista”, Asclepio, 71(1): p255. https://doi. org/10.3989/asclepio.2019.07.

RESUMEN: A lo largo del Franquismo la discapacidad apareció inmersa en un complejo discurso en el que confluían, entre otras cosas, las ideas científicas, la sensibilidad hacia las personas portadoras de "deficiencias", el interés económico, y el adoctrinamiento político. El objetivo de este trabajo es analizar el componente "educativo" de este discurso y poner de manifiesto cómo dicho ingrediente no estuvo únicamente dirigido a mejorar las condiciones de vida de las personas catalogadas de "inválidas", sino que pretendió también obtener el compromiso, la colaboración y la complicidad del conjunto de la ciudadanía para establecer medidas destinadas a reducir el impacto negativo que, según se sostenía, provocaba la discapacidad. Así mismo, mostraremos cómo dicho discurso, que en ocasiones adquirió tintes propagandísticos, contribuyó a que en la España franquista creciese una forma de contemplar la discapacidad que no siempre fue favorable a los intereses de las personas con discapacidad.

PALABRAS CLAVE: Historia de la discapacidad, España, Franquismo, educación sanitaria, propaganda sanitaria.

\section{POPULARIZING NEW IDEAS ABOUT HUMAN DIVERSITY: THE EDUCATIONAL DIMENSION OF THE DISCOURSE ON DISABILITY IN FRANCO'S SPAIN}

ABSTRACT: Under Francoism, disability appeared immersed in a complex discourse in which converged, among other things, scientific ideas, sensitivity towards people carrying "deficiencies", economic interest, and political indoctrination. This paper aims to analyse the "educational" component of this discourse and underscore that not only pretended to improve the living conditions of people listed as "invalid"; but also to obtain the commitment, collaboration and complicity of the whole citizenship to implement measures to reduce the alleged negative impact of disability. Furthermore, we will show how this discourse, which sometimes acquired propaganda dyes, contributed to developing in Franco's Spain a climate regarding disability that it has not always been favourable to the interests of people with disabilities.

KEY WORDS: History of disability, Spain, Francoism, Health Education, Popularization of Medical Knowledge

Copyright: @ 2019 CSIC. Este es un artículo de acceso abierto distribuido bajo los términos de la licencia de uso y distribución Creative Commons Reconocimiento 4.0 Internacional (CC BY 4.0). 


\section{INTRODUCCIÓN}

El cambio de régimen político operado tras el desenlace de la Guerra Civil española (1936-1939) supuso la implantación en España de una dictadura que, como es sabido, además de generar un aparato burocrático destinado a promoverse y legitimarse, hizo de la defensa de la tradición y del catolicismo sus principales referentes. En el contexto de este "Nacionalcatolicismo" (Oltra y De Miguel, 1978, p. 53) el discurso sobre la discapacidad adquirió un carácter complejo (Martínez-Pérez y Del Cura, 2015). Sin duda, la propia estructura multifacética del fenómeno -en cuya composición intervienen como poco ingredientes sociales, culturales, económicos y científicos- contribuyó a que confluyeran en dicho discurso un flujo importante de ideas e intereses procedentes de distintos ámbitos. Políticos, economistas, médicos, juristas, religiosos, pedagogos, personas portadoras de "deficiencias" y familiares de estas últimas, participaron en la elaboración de una visión de la discapacidad, de lo que representaba y del modo de paliar sus efectos sobre la sociedad y los individuos, en la que ocupó un lugar destacado -tanto en el terreno teórico como en el de las ejecuciones prácticas- el deseo por "educar", por inculcar a la ciudadanía una cierta forma de interpretar la discapacidad y de reaccionar ante ella.

El objetivo de este trabajo es analizar el componente "pedagógico" de este discurso, especialmente el emanado de las ideas y prácticas que los médicos y los poderes públicos sostuvieron acerca del fenómeno de la discapacidad. Pretendemos poner de manifiesto cómo esa labor "educativa" no estuvo únicamente dirigida a mejorar las condiciones de vida de las personas catalogadas de "inválidas", sino que persiguió también obtener el compromiso, la colaboración y la complicidad del conjunto de la ciudadanía a la hora de establecer medidas destinadas a reducir el impacto negativo que, según se sostenía, provocaba la discapacidad sobre la prosperidad de determinadas personas, de sus familias y de la colectividad. Así mismo, intentaremos mostrar cómo dicho discurso, que en ocasiones adquirió tintes claramente propagandísticos, contribuyó a que en la España franquista creciese una forma de contemplar la discapacidad que afectaba a la imagen social de las personas portadoras de lo que se consideraban como "deficiencias" físicas, sensoriales o intelectuales, y que contenía ingredientes no siempre claramente favorables a sus intereses.
Al objeto de exponer lo que acabamos de plantear como objetivos fundamentales de este artículo, nos ocuparemos en primer lugar de examinar cómo la discapacidad encajó en el programa político del régimen franquista. A continuación, pondremos de manifiesto cómo las nuevas ideas que estaban promoviendo los expertos acerca del significado de la discapacidad, y el modo de gestionar los problemas que se consideraba que este fenómeno llevaba aparejado, e mpezaron a ser incorporadas a la acción desarrollada por el gobierno franquista, especialmente en el ámbito de la discapacidad física. En tercer lugar, exploraremos el modo en que estas ideas fueron trasladadas a la población mediante una acción de "educación sanitaria". Finalmente mostraremos cómo esta última contenía mensajes que, potencialmente al menos, podían perjudicar a las personas clasificadas como "incapaces".

\section{EL TRABAJO COMO VALOR Y LA DISCAPACIDAD COMO PROBLEMA EN EL "NUEVO ESTADO"}

Uno de los aspectos de la organización social a los que más relevancia otorgó el régimen franquista fue el del trabajo. En plena Guerra Civil, la actividad laboral fue ya objeto de regulación por parte del bando rebelde en una de las "leyes fundamentales" sobre las que se deseaba construir el "Nuevo Estado". El Fuero del Trabajo, centro propulsor del que irradió la política social del franquismo (González Sánchez, 1997, p. 117), concebía la actividad laboral como "la participación del hombre en la producción" al objeto de contribuir a su mantenimiento y desenvolvimiento como ciudadano y "al mejor desarrollo de la economía nacional" (Declaración I.1.) ${ }^{1}$. Dicha participación se presentaba como "un deber impuesto al hombre por Dios" para el "cumplimiento de sus fines individuales y la prosperidad y grandeza de la Patria" (Declaración I.3.), y como un "deber social" que había de ser "exigido inexcusablemente" a "todos los españoles no impedidos" (Declaración I.5.).

La importancia otorgada al trabajo, reconocido también como un derecho de los españoles, era además reforzada con la concesión de una importante ventaja para quien lo realizaba: el trabajo se consideró un "título suficiente para exigir la asistencia y tutela del Estado" (Declaración I.8. y I.6). En consecuencia, el nuevo régimen se comprometía a amparar al trabajador en el caso de que una desgracia le im- 
pidiera desarrollar su actividad laboral (Declaración II.1.; Declaración X.1.). Para cumplir con este compromiso el régimen aseguraba, lo que es muy relevante para nuestros objetivos, que se incrementarían, entre otros, los seguros sociales de vejez, accidentes de trabajo y enfermedades profesionales e invalidez (Declaración X.2.)

La preocupación del gobierno totalitario por responder a esto último, se expresó tempranamente en el ámbito legislativo en relación con uno de los principales orígenes de la discapacidad: la siniestralidad laboral. En 1940, en el marco del Reglamento general de Seguridad e Higiene en el Trabajo ${ }^{2}$, las nuevas autoridades mantuvieron vigente casi en su totalidad el contenido del texto refundido de la legislación de accidentes de trabajo que se había decretado en $1932^{3}$. Esto último es relevante porque esta ley contemplaba algunas medidas significativas para el devenir de los trabajadores que, a causa de un accidente laboral, se convertían en personas con discapacidad. Además de establecer que, en caso de incapacidad permanente de la víctima, las indemnizaciones habían de ser abonadas en forma de renta (Cap. II. Art. 21), la ley contemplaba su "readaptación funcional" (Cap. IV. Art. 36). Esto representaba conservar un planteamiento que, especialmente durante el período de la dictadura de Primo de Rivera, había favorecido el desarrollo en España de actuaciones destacadas en relación con la recuperación de personas víctimas de accidentes laborales (Martínez-Pérez 2001, 2006b, 2009; Martínez-Pérez y Porras, 2006; Martínez-Pérez y Del Cura, 2013), y que implicaba aceptar que era posible transformar a una persona considerada como "inválida" para el trabajo en alguien apto para la actividad laboral. Con la ayuda de las nuevas técnicas procedentes de la medicina -quirúrgicas y rehabilitadoras, principalmente- era posible devolver o aproximar el cuerpo alterado por el accidente a la "normalidad" anatómica y facilitar así que, tras un proceso que incorporaba en ocasiones el aprendizaje de un nuevo oficio ajustado a su condición física, una persona pudiera convertirse otra vez en un trabajador, en aquello que ahora el franquismo prefería denominar "productor" (Ruiz Carnicer, 2004, p. 87).

No obstante, en los primeros años de la dictadura, este programa no se desarrolló en la práctica. La readaptación funcional se centró sobre todo en la fase de actuación médica, sin que encontrara clara continuidad en la etapa destinada a las actuaciones educativas. Este hecho se debió, en gran medida, a las dificultades que hubo tras la guerra para poner en marcha adecuadamente las instituciones en las que ese tipo de actuaciones se llevaban a cabo, pero también estuvo determinado por un cierto desaliento, presente ya durante la etapa republicana, acerca de la utilidad de esa fase en el proceso de reinserción de una víctima de la siniestralidad laboral en la tarea productiva. Una muestra significativa de ello es el hecho de que la institución que había representado de una manera más destacada esa orientación reeducadora dentro de nuestras fronteras -el Instituto de Reeducación Profesional (Bachiller Baeza, 1985)-, concedió entre 1940 y 1945 una posición dominante a la "sección médica" frente a las secciones a las que les estaba atribuida la parte destinada a reeducar y procurar la reinserción de las personas a la vida laboral: la "técnica" y la "administrativa" (Palacios, 1990; Martínez-Pérez, 2006a).

El resto de medidas legislativas que se aprobaron estos primeros años, y que contemplaban intervenciones dirigidas hacia la discapacidad, no hicieron hincapié en el componente educativo (Martínez-Pérez y Del Cura, 2015, pp. 809-811). Ni siquiera la Lucha Sanitaria Nacional contra la Invalidez, aprobada en $1949^{4}$, sirvió para impulsar de manera determinante en la práctica una forma de abordaje de la discapacidad en la que el componente reeducador ocupara un lugar relevante. Aunque en su preámbulo se reconocía que era "muy elevado" el número de "inválidos en la infancia y la juventud que con un tratamiento inmediato y vigilancia constante podrían ser recuperados, con gran ventaja para los intereses económicos de la nación y personal de los enfermos y familiares", y se hablara de la necesidad de "orientar y organizar la asistencia de inválidos en centros especializados", estos ciudadanos continuaron siendo un colectivo deficitariamente atendido y con escasa posibilidad de unirse a la población activa. La preocupación del gobierno por la discapacidad se centró fundamentalmente en la resolución de las anomalías corporales y el mantenimiento de un sistema de ayuda social expresado significativamente en el caso de las víctimas de la siniestralidad laboral (MartínezPérez, 2017). Hubo que esperar hasta la década de los 50 para que el régimen de Franco diera muestras de recuperar una concepción de la intervención sobre la discapacidad en la que la labor encaminada a capacitar a los individuos "inválidos" para aprender un nuevo oficio en función de sus deficiencias corporales se incorporara con fuerza al discurso que estamos analizando. En ella, nuevas técnicas, como la rehabi- 
litación o la fisioterapia, iban a encontrar cabida e iban a verse impulsadas ${ }^{5}$.

\section{LA EMERGENCIA DE LA REEDUCACIÓN EN LA DÉCADA DE LOS CINCUENTA}

A finales de los cincuenta se consideró que la Lucha Sanitaria contra la Invalidez no estaba siendo eficaz (Piga, 1959, p. 317). Por ello, con el aliento favorable que suponían los informes de las comisiones de organismos internacionales -especialmente de la Organización Mundial de la Salud- acerca de la rehabilitación (Brègain, 2018, pp. 114-163), y con las recomendaciones que algunos de los expertos que las componían hicieron tras visitar España (Aguila Maturana, 2000, p. 135; Ballester, 2012; Toledo Marhuenda y Ballester Añón, 2015, Brègain, 2018, pp. 211-215), se empezó a trabajar en la elaboración de un programa de actuaciones para organizar la rehabilitación (Safford y Hanson, 1957). En 1957 se publicó el decreto de creación del Patronato Nacional de Rehabilitación y Reeducación de Inválidos ${ }^{6}$, en cuya denominación se dejaba ya constancia de la voluntad por incorporar elementos "educativos" al proceso de recuperación de las personas consideradas discapacitadas. Ya no se pretendía únicamente tratarlas clínicamente para dotarlas de "normalidad" corporal, sino que, como los términos "rehabilitación" y "reeducación" dejaban claro, se aspiraba a su "recuperación social y laboral" (Art.3).

Este clima de cambio se expresó también de manera conspicua en el I Symposium Médico-Social dedicado a debatir sobre "Rehabilitación social del presunto inválido y Seguridad Social", que se celebró en Madrid entre los días 27 y 28 de marzo de 1958 organizado por el Instituto Nacional de Previsión ${ }^{7}$. En esta reunión de trabajo, en la que participaron buena parte de los expertos que en ese momento tenían algún tipo de responsabilidad o relación con la asistencia a las personas con discapacidades, se pretendía buscar nuevas realizaciones que la mejoraran, introduciendo acciones "pre y postcurativas" que la complementaran. En ese sentido, se planteaba que la consecución de la rehabilitación y reeducación de las personas con discapacidad representaba un objetivo a alcanzar para las "nuevas y prometedoras etapas de la Seguridad Social Española” (Lamas, 1959, p. 14).

El nuevo modo de gestionar la discapacidad que trataba de introducirse en España se hizo patente du- rante el Symposium en el modo en que se emplearon los términos rehabilitación, reeducación y readaptación. Dichas palabras se utilizaron como sinónimos para hacer alusión al conjunto de actuaciones que debían permitir "reducir al mínimo las alteraciones que sufren las personas físicamente disminuidas y lograr el máximo de aptitudes físicas y mentales y su integración a la función social" (Bravo, 1959, p. 299). La rehabilitación pretendía, por tanto, ir más allá de la mera curación de las lesiones. También buscaba su prevención y restituir las funciones corporales con el ánimo de poder llevar a cabo una reeducación profesional que facilitara la inclusión social. Se trataba de conseguir también restablecer en los individuos "inválidos" la voluntad de trabajo y probabilidad de ganar un salario (López Fernández y Bataller Sallé, 1959, p. 305), logrando de este modo que "el futuro de la vida profesional y social del incapacitado" pudiera desarrollarse "huyendo de soluciones caritativas y simplistas del sistema de subvenciones, pensiones, etcétera" (López Fernández y Bataller Sallé, 1959, p. 307). En ese sentido la consecución del "reempleo", de la inserción completa en la actividad laboral de personas con deficiencias, debía ser considerada el "colofón" de la rehabilitación terapéutico-médica (Vega Díaz, 1959, p. 100).

\section{MODIFICANDO COMPORTAMIENTOS $Y$ ACTITUDES: EDUCACIÓN SANITARIA Y DISCAPACIDAD}

La reeducación de los "inválidos" emergía así en la España franquista como un componente relevante de la solución a los problemas que la discapacidad planteaba a la sociedad española, especialmente a los relacionados con la producción. Por eso iba a tratar de crearse "un clima de interés hacia la rehabilitación" (Sanchis-Olmos, 1959, p. 325). Se consideraba que era creciente "la necesidad de educar al público, tanto profano como profesional (...) con el fin de que adopten una actitud conveniente en relación con la invalidez física y comprendan lo que significa la readaptación"; así como hacerle comprender que "si se actúa correctamente, una persona física disminuida puede volver a ser un miembro útil de la colectividad por poco que se le ayude a utilizar de forma completa las aptitudes que le restan y que se le dé el estímulo necesario en su trabajo" (Bosch Marín, 1959, p. 40). Por ello, en España, donde "la concepción moderna de la rehabilitación" era todavía poco conocida, "la educación del público, en lo que concierne a dere- 
chos, responsabilidades y posibilidades de los inválidos, constituye una tarea extremadamente importante" (Bosch Marín, 1959, p. 42).

Se trataba, por tanto, en gran medida de llevar a cabo una labor propagandística sobre la rehabilitación similar a la que se realizaba con el ánimo de convencer a la población sobre las bondades del nuevo régimen y de persuadirla para colaborar en la tarea de mantenerlo y desarrollarlo 8 . Era necesario, en efecto, no sólo dar a conocer las nuevas ideas sobre la discapacidad y las posibilidades existentes para controlar sus efectos indeseables, sino también, como veremos, procurar transformar los comportamientos y las actitudes de los españoles respecto a ella y buscar su colaboración para poder alcanzar sus metas. Según lo expresaba un participante en el simposio, era necesario realizar

Extensas Campañas de Educación Sanitaria Popular en materia de Rehabilitación, que lleguen a todos los confines del país y alcancen a todos los estratos de la sociedad; (...) que estimulen la colaboración de las autoridades, empresas, sindicatos, entidades y aun particulares en la tarea común de la Rehabilitación, considerada como un deber de todo ciudadano en beneficio de sus semejantes más necesitados de ayuda" (Bravo, 1959, p. 303).

De este modo, bajo el término de "educación sanitaria popular"9, los médicos planteaban la necesidad de realizar una labor de divulgación para inculcar en la población las novedades médicas y comprometerla en la realización de las prácticas relacionadas con ellas ${ }^{10}$.

Es preciso indicar que la valoración durante el franquismo de la vulgarización de los conocimientos médicos como forma de transformar comportamientos sanitarios no parece haber sido homogénea. Se ha apreciado cómo la desconfianza inicial ante su eficacia fue transformándose paulatinamente en una percepción más favorable (Perdiguero-Gil, 2015). Ya en 1951, el doctor Julio Bravo (1894-1986) -Jefe de Propaganda de la Dirección General de Sanidad (Perdiguero, Ballester y Castejón, 2007, p. 309-311)-, afirmaba que la validez de la "propaganda o divulgación sanitaria" era reconocida "por todo el mundo" a la hora de "difundir entre el pueblo conceptos y conocimientos difíciles de comprender de no ser puestos a su alcance de manera sencilla, gráfica y llamativa" (Bravo, 1951, pp. 4-5). No debe de extrañar que esta confianza en el papel que la propaganda poseía para transmitir información sobre una cuestión, y para generar comportamientos y actitudes en relación con ella, se utilizara para tratar de establecer en España una atmósfera favorable respecto a los nuevos planteamientos que se estaban formulando sobre el fenómeno de la discapacidad.

\subsection{DivUlgaCión a traVÉS DE LA PALABRA IMPRESA}

Julio Bravo había llamado la atención en 1951 sobre la relevancia que poseían los folletos entre los medios de propaganda que clasificaba como de "palabra impresa". En este sentido, destacaba cómo la Dirección General de Sanidad los estaba utilizando para realizar una "alta divulgación" dirigida a los médicos "al objeto de ponerles al tanto de los problemas sanitarios de más interés o actualidad en cada momento" (Bravo, 1951, pp. 19-20) ${ }^{11}$. En uno de ellos, publicado en 1963, el doctor Manuel Oñorbe Garbayo -Jefe de los Servicios de Rehabilitación Sanitaria de la Dirección General de Sanidad y Secretario General del Patronato de Rehabilitación y Recuperación de Inválidos ${ }^{12}$ - se iba a ocupar de lo que consideraba "un tema que en los momentos actuales apasiona". Se refería al "problema de la invalidez y la posible rehabilitación y recuperación física, familiar, social y laboral de los deficitarios físicos o psíquicos" (Oñorbe Garbayo, 1963$, p. 3$)^{13}$. Según indicaba, el "alarmante incremento del número" de "incapacitados" habría hecho surgir lo que se había dado en llamar la "tercera fase de la Medicina", esa que, como complemento de la Medicina preventiva y de la curativa o terapéutica, vendría representada por "la Medicina rehabilitadora". Ello habría sido posible por la coincidencia de dos hechos mutuamente influyentes: "el mejoramiento de los métodos inicialmente empleados en la rehabilitación, y la iniciación entre las autoridades públicas y los particulares de una nueva actitud positiva frente a los problemas de los inválidos e incapacitados parciales" (Oñorbe Garbayo, 1963, p. 6). La rehabilitación era presentada como el resultado de un trabajo en equipo orientado básicamente a "reintegrar al individuo, hasta donde sea posible, su capacidad física, mental, vocacional, laboral, familiar, social y económica, dentro del límite de su incapacidad". Representaba una tarea que se dirigía tanto a los "disminuidos que antes de llegar a tal situación fueron seres sanos y normales", como a los que "no fueron nunca normales" (Oñorbe Garbayo, 1963, p. 6-7).

Junto a la divulgación de la idea de que la readaptación se dirigía a la "reintegración" social de todas 
las personas con deficiencias, Oñorbe pasaba a resaltar que la rehabilitación era capaz de devolver a los "disminuidos físicos", y siempre que "se les faciliten los medios apropiados para ello", al estatus de "elementos activos de la vida económica del país, en vez de constituir una carga para su familia, para la sociedad y para el Estado" (Oñorbe Garbayo, 1963, pp. 7-8). De este modo, una idea de alcance se transmitía a la sociedad. La discapacidad no era un fenómeno estable. La intervención médica podía modificar la condición de "inválido" de un ciudadano y, con ello, aliviar uno de los componentes de la discapacidad que, como vimos arriba, formaba parte de la visión que el franquismo tenía de ella: la de ser un lastre para el desarrollo de la Patria. En efecto, además de sostener que las personas con deficiencias debían ser objeto de atención en una sociedad en la que destacaba "el sentido cristiano de la vida" y el "valor espiritual de los hombres ante los ojos de Dios", Oñorbe señalaba que la rehabilitación podía contribuir al "saneamiento de la sociedad, disminuyendo el número de elementos inactivos y parásitos, cuya influencia moral es verdaderamente nefasta" (Oñorbe Garbayo, 1963, pp. 8-9). En ese sentido, ponía de manifiesto que

el reintegro del incapacitado a su antiguo puesto de trabajo, situación ideal si ello es posible, o al nuevo que sus condiciones físicas le permiten desempeñar, una vez orientado y preparado científicamente, no sólo beneficia al recuperado física y mentalmente, al verse reintegrado a la vida ordinaria como hombre útil a la sociedad y para su familia, sino que al mismo tiempo coopera, conjuntamente con los demás recuperados, a mejorar la productividad de la nación, ya que ha quedado demostrado en repetidas encuestas que los inválidos recuperados y preparados para ello dan en su nuevo puesto de trabajo, si es el adecuado a sus posibilidades, un rendimiento similar al de un hombre totalmente normal." (Oñorbe Garbayo, 1963, pp. 9-10).

De este modo, la rehabilitación era presentada como una herramienta fundamental para el desarrollo económico del país. Su implementación representaba una forma, no ya de cumplir con los principios morales que el Nacionalcatolicismo señalaba como guía para la configuración del "Nuevo Estado", sino también, de aliviar las arcas públicas y de incrementar la tasa productiva.

La capacidad que tenía la rehabilitación para situar en condiciones de trabajar a personas que se podía pensar que no eran capaces de hacerlo hizo que emergiera de manera explícita una exigencia hacia las personas clasificadas como "inválidas": la de tener "el deber, en relación con la sociedad, de contribuir a la prosperidad económica de su país en cuanto les permita su readaptación y su formación profesional." (Oñorbe Garbayo, 1963, p. 8). Ahora que era posible cambiar de estatus a las personas tenidas por "inválidas", una nueva obligación les iba a ser impuesta: la de someterse al proceso de rehabilitación si su situación era susceptible de ello y el Estado les ofrecía los medios para realizarlo. En este sentido, el Decreto de 13 de abril de 1961, por el que se organizaba "el aseguramiento de las enfermedades profesionales y la Obra de Grandes Inválidos y Huérfanos de fallecidos por accidentes de trabajo o enfermedad profesional", estableció una medida coercitiva. En su artículo 28.2 se consignaba que el trabajador accidentado o enfermo profesional que se negara a "someterse a rehabilitación", así como el que no cumpliera "fielmente las prescripciones médicas", podía "ser suspendido en la percepción económica que viniere disfrutando en concepto de indemnización por incapacidad temporal o permanente, o sancionado con la disminución de ésta"14. La vulgarización servía así para trasladar a los españoles una consecuencia de la rehabilitación muy significativa: la posibilidad de aplicar medidas económicas sancionadoras a aquellas personas con discapacidad que no estuviesen dispuestas a someterse a las actuaciones rehabilitadoras.

La necesidad de transmitir la idea de que las personas "inválidas" podían dejar de serlo afectó también al modo en que se recomendaba referirse a ellas. Una de las vías de divulgación escrita -la prensa general- era aprovechada por Oñorbe para darlo a conocer a la sociedad. En una entrevista concedida con motivo de la celebración en Sevilla de una reunión científica sobre rehabilitación, Oñorbe corregía al periodista que le interrogaba sobre el papel de la rehabilitación sobre los "inválidos", y le indicaba que esa palabra debía sustituirse por la de "incapacitados", reservando la primera para aquel para el que "no hay posibilidad de recuperarlo para la vida activa"15.

Planteamientos similares a los que estamos poniendo de manifiesto se realizaban también en uno de los folletos elaborados por el Patronato de Rehabilitación de Inválidos ${ }^{16}$. En él la discapacidad se presentaba como un fenómeno frecuente, del que nadie estaba libre, cuya aparición estaba habitualmente relacionada con la poliomielitis, el reumatismo, los accidentes, las hemiplejías y las enfermedades congénitas. Se llamaba la atención asimismo sobre el hecho de que gran parte 
de los "incapacitados" podían ser adaptados para la convivencia social, o recuperados para el trabajo, mediante un adecuado tratamiento. Éste implicaba, en un gran número de casos, recurrir a la cirugía y la ortopedia, pero se indicaba también que había otros tratamientos de utilidad, como la terapia ocupacional. Se advertía luego de que si una persona rehabilitada quedaba imposibilitada para volver a su anterior ocupación había que adaptarla a una nueva profesión ajustada a su condición física y a su vocación, para lo que debía recibir instrucción en centros de formación profesional o en talleres normales. Se hacía asimismo hincapié en la necesidad de procurar la incorporación al mercado laboral del trabajador rehabilitado. El folleto concluía llamando la atención sobre la inversión que suponía dedicar dinero a la recuperación de los "inválidos", al representar un ahorro en pensiones y ayudas, aunque también advertía que la labor de rehabilitación debía emprenderse como una manifestación de derecho humano y solidaridad cristiana más que como un negocio o deber social.

El ideario del régimen impregnaba así la propaganda sobre la rehabilitación. Llamar la atención sobre las posibilidades de corregir las deficiencias anatómicas y funcionales de las personas inválidas conectaba con la consideración del trabajo como un deber y un derecho, y con los referentes católicos del "Nuevo Estado". Las personas discapacitadas adquirían así una dimensión política al convertirse en objeto de unas actuaciones que se incardinaban con los principios fundamentales del régimen. Su posición era ahora, por tanto, muy delicada. El Estado afirmaba su capacidad para rehabilitarlos y ellos se veían obligados a hacer lo posible para convertirse en ciudadanos válidos para la actividad laboral. En cierto modo, al ponerse de relieve que podían ser "educados" para participar en la tarea de incrementar la riqueza de la Patria, habían pasado a simbolizar la idea de que ningún ciudadano tenía excusas para eludir su compromiso con esa labor, que nadie podía negarse a cumplir la obligación de llegar a ser un "productor".

Pero el discurso que se estaba generando en torno a la discapacidad contenía también otros ingredientes destacados que la "educación sanitaria" contribuiría a divulgar. Como Oñorbe ponía de manifiesto, la Medicina preventiva se consideraba, la "primera etapa de la rehabilitación", puesto que al "evitar las enfermedades y accidentes suprimimos las invalideces que unas y otras dejan" (Oñorbe Garbayo, 1963, p. 10). Esto iba a determinar que, ya con anterioridad al es- tallido de la Guerra Civil, existiese, como apuntamos arriba, una relevante actividad de propaganda dirigida a promover entre la población comportamientos encaminados a la prevención. Muestra de ello es la labor desarrollada para intentar reducir las tasas de una de las principales fuentes de discapacidad: la siniestralidad laboral.

\subsection{El VAlor De LA imagen: DivUlgar mediante CARTELES}

Desde los años 20 las estrategias de prevención de los accidentes del trabajo cobraron auge dentro de nuestras fronteras, y en ellas la propaganda fue un ingrediente destacado. Uniéndose a la tendencia en boga en ese periodo, la prevención de la siniestralidad laboral hizo de los carteles uno de sus principales recursos. Convertidos desde comienzos del siglo XX en una de las vías por las que España se conducía hacia la modernidad, los carteles se constituyeron pronto en una fuerza poderosa para modelar la opinión pública. No debe extrañar que, habiéndose contrastado su utilidad para la publicidad comercial o para la difusión de las ideas políticas, a partir de 1917 se considerara que el cartel podía ser un procedimiento útil para procurar mejorar la salud y el potencial de la población. El cartel pasó a representar un componente significativo de las campañas de educación que las instituciones sanitarias concibieron para difundir los conocimientos científico-técnicos, influir en las actitudes, e intentar modificar los comportamientos de la población española (Perdiguero-Gil y Castejón Bolea, 2012, p. 9).

Por lo que respecta a los carteles relacionados con la prevención de la siniestralidad laboral ese triple objetivo incorporaba desde el principio un componente que nos interesa destacar: el mensaje de que el obrero podía tener una responsabilidad en el accidente. Ya en las primeras propuestas de carteles diseñados en el Instituto de Reeducación Profesional de Madrid en la década de los años 20 y 30 se aprecia este rasgo que tenía que ver con el modo en que se analizaban las causas de la siniestralidad laboral y se destacaba la relevancia en ellas del "factor humano" (Martínez-Pérez, 1994 y 2001). El accidente, y por ello la muerte o la "invalidez" del obrero, podían ser debidos a distracciones o a un exceso de confianza al desempeñar sus tareas (Imágenes 1, 2, 3). De este modo, se lanzaba a la sociedad española un mensaje que convertía a las víctimas de los accidentes del tra- 


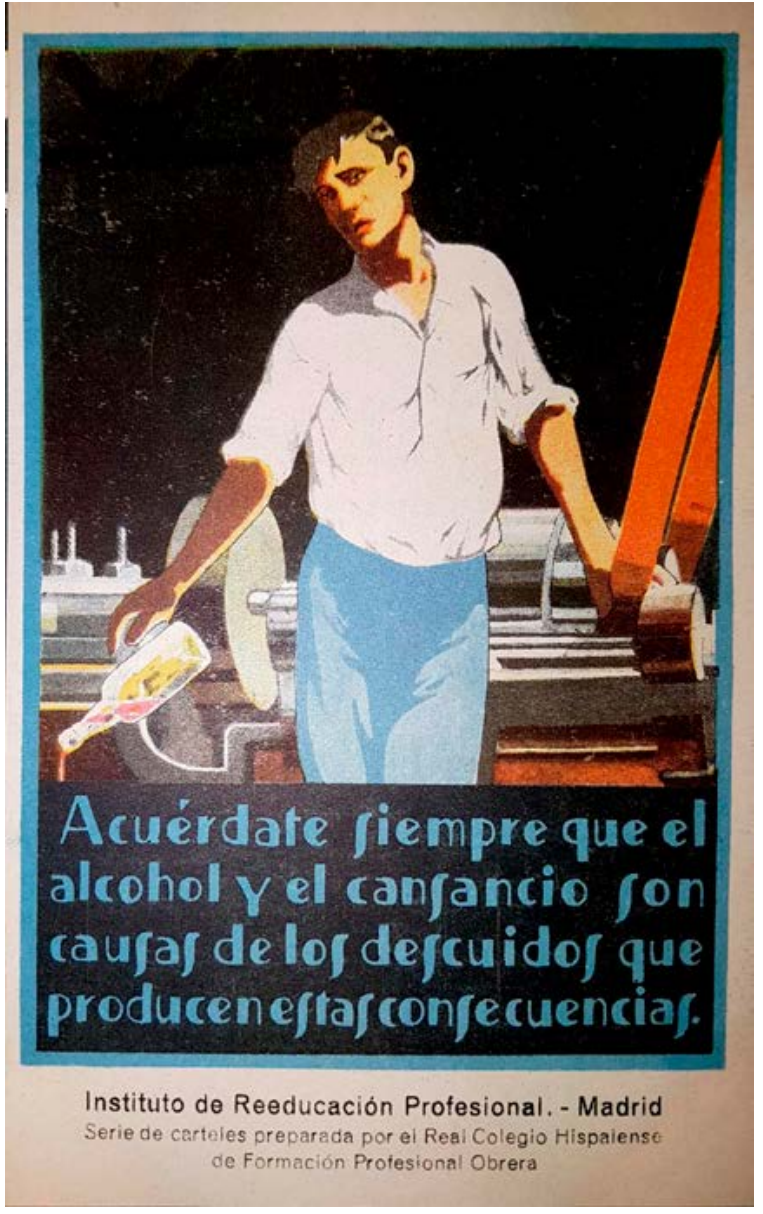

Imagen 1. Cartel del Instituto de Reeducación Profesional de Madrid. Años 20-30. Fuente: Colección personal del Doctor Luis Nájera Angulo.

bajo en responsables, al menos en parte, de su desgracia (Martínez-Pérez, 1997, pp. 134-135).

Este rasgo, que fue común en Europa a lo largo del período que abarca este trabajo (Menéndez-Navarro, 2015, p. 22), estuvo también muy presente en la España franquista. La preocupación por la prevención de los accidentes del trabajo se expresó muy tempranamente con la promulgación en 1940 del Reglamento general de Seguridad e Higiene en el Trabajo ${ }^{17}$. En su preámbulo se afirmaba que, habiéndose resuelto la reparación económica del daño causado, lo que correspondía ahora era disminuir el número y la gravedad de los accidentes mediante una intensa labor preventiva. Para tratar de mejorarla, y respondiendo a una de las conclusiones del Primer Congreso Nacional de Medicina y Seguridad del Trabajo celebrado en Bilbao en agosto de $1943^{18}$, se creó en 1944 el Instituto Nacional de Medicina, Higiene y Seguridad del Trabajo. El nuevo

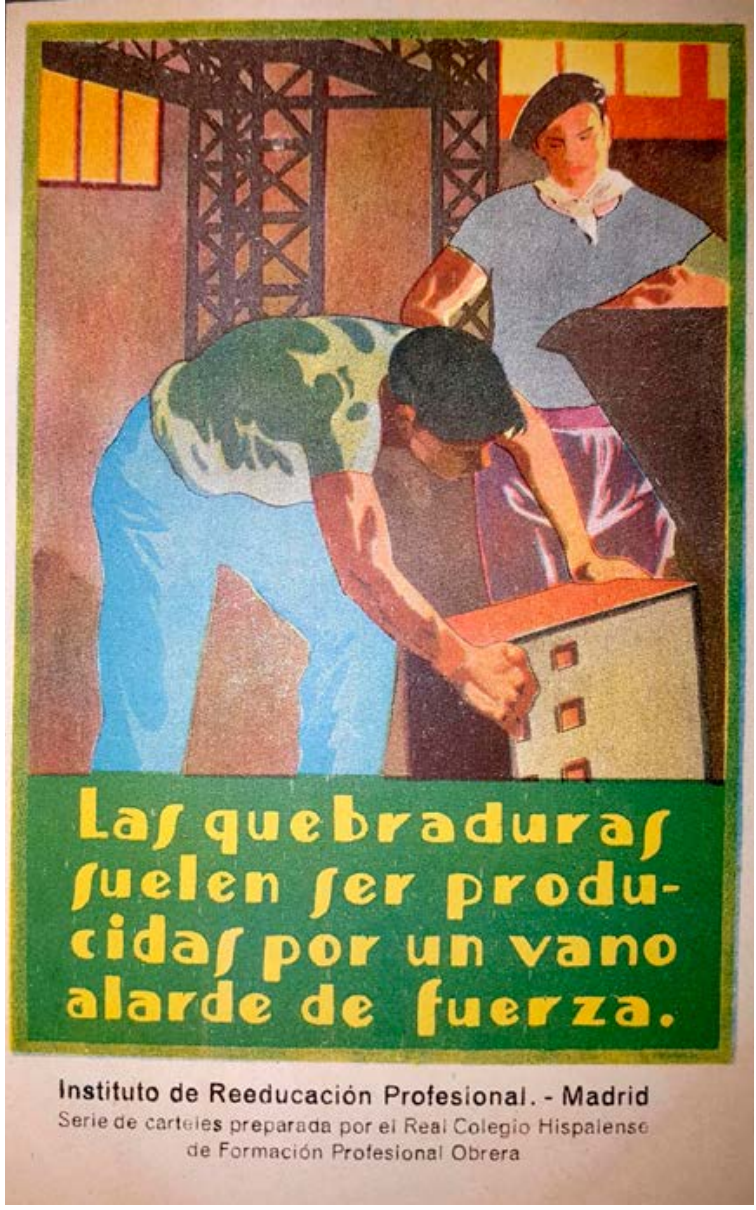

Imagen 2. Cartel del Instituto de Reeducación Profesional de Madrid. Años 20-30. Fuente: Colección personal del Doctor Luis Nájera Angulo.

centro nacía con el objetivo de servir como un lugar de investigación que proporcionara "el conocimiento necesario para inspirar una legislación eficaz y una propaganda efectiva, especialmente en materia de prevención de accidentes del trabajo". Se esperaba que el Instituto contribuyera a "llenar una importante misión en la esfera laboral" para lograr "una efectiva elevación en la producción nacional" y "un mejoramiento de vida de los trabajadores"19. Con ese objetivo, el Instituto se ponía al "servicio de las empresas y del obrero", ya que, según expresaban sus miembros en la revista que editaba la propia institución, no constituía "un mero organismo sanitario" sino que era también un organismo "económico y social". Competía por ello al Instituto "la progresiva educación de los obreros en cuanto a una eficaz colaboración de la salud y de la enfermedad", para lo que ofrecía sus recursos a empresas y trabajadores poniéndolos al servicio de una acción "educativa y difusora de los más modernos métodos preventivos"20. 


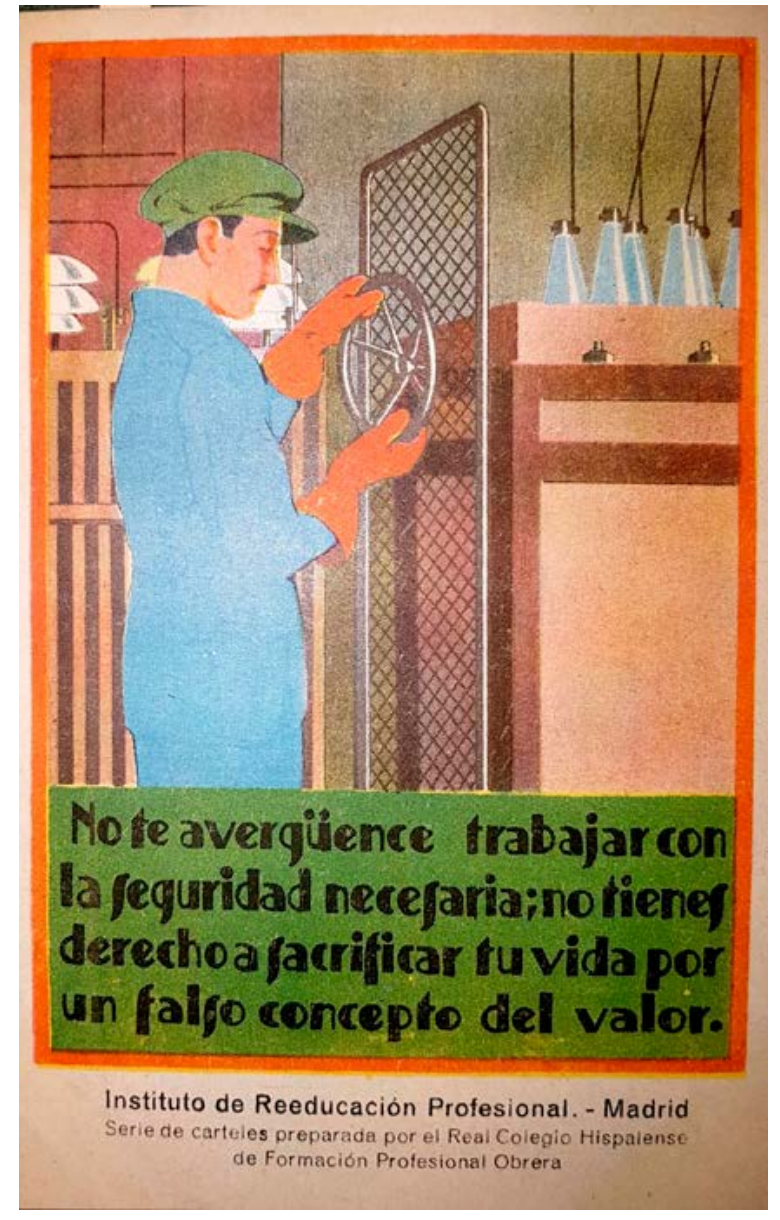

Imagen 3. Cartel del Instituto de Reeducación Profesional de Madrid. Años 20-30. Fuente: Colección personal del Doctor Luis Nájera Angulo.

Un papel significativo, en ese sentido, le correspondía a su sección de divulgación, que incluía entre sus programas los de "información general sobre las medidas higiénicas y de seguridad" y de "educación preventiva y educación sanitaria". A través de ellos se trataba de vencer "la apatía, la indisciplina, la incomprensión del capital, las actitudes obreras que impidan el desarrollo de una vida operante en la industria, la falta de educación social y el escepticismo". Asimismo, se pretendía obtener el respeto a las medidas preventivas, médicas y de seguridad, la disminución de los accidentes, un mayor rendimiento productivo y un mejor nivel en la actitud física del obrero ${ }^{21}$. Se trataba, por tanto, de inculcar en los productores la idea de la necesidad y la conveniencia de evitar los accidentes, y de persuadirlos para, al tiempo que se reducía su conflictividad laboral, mejorar la producción y reducir los costes de la discapacidad. A través de ello, se intentaba también realizar ese control social que la in- tervención gubernamental sobre la discapacidad ayudaba a conseguir (Martínez-Pérez, 2017).

El cartel se presentaba así como un buen soporte para conseguir esos objetivos. José Vidaurreta, que dirigió la sección de archivo y biblioteca del Instituto ${ }^{22}$, indicaba en 1947 que, al objeto de prevenir la siniestralidad laboral, se había superado la fase de protección mecánica de la maquinaria. Era preciso por tanto pasar a adoptar "dos órdenes de medidas que, dirigidas al factor humano, deben ser consideradas como de la más elevada importancia". Se refería "a la orientación, selección y formación profesionales y a la educación preventiva" (Vidaurreta, 1947, p.49). Respecto a esto último, consideraba al cartel como "un excelente medio de acción educativa y propaganda", creando una "personalidad consciente del peligro" que "lleva al individuo a ser prudente y a actuar oportunamente" (Vidaurreta, 1947, p.50).

No debe extrañar que esta relevancia concedida al cartel como medio para modificar comportamientos, impulsara la convocatoria de concursos con el obje-

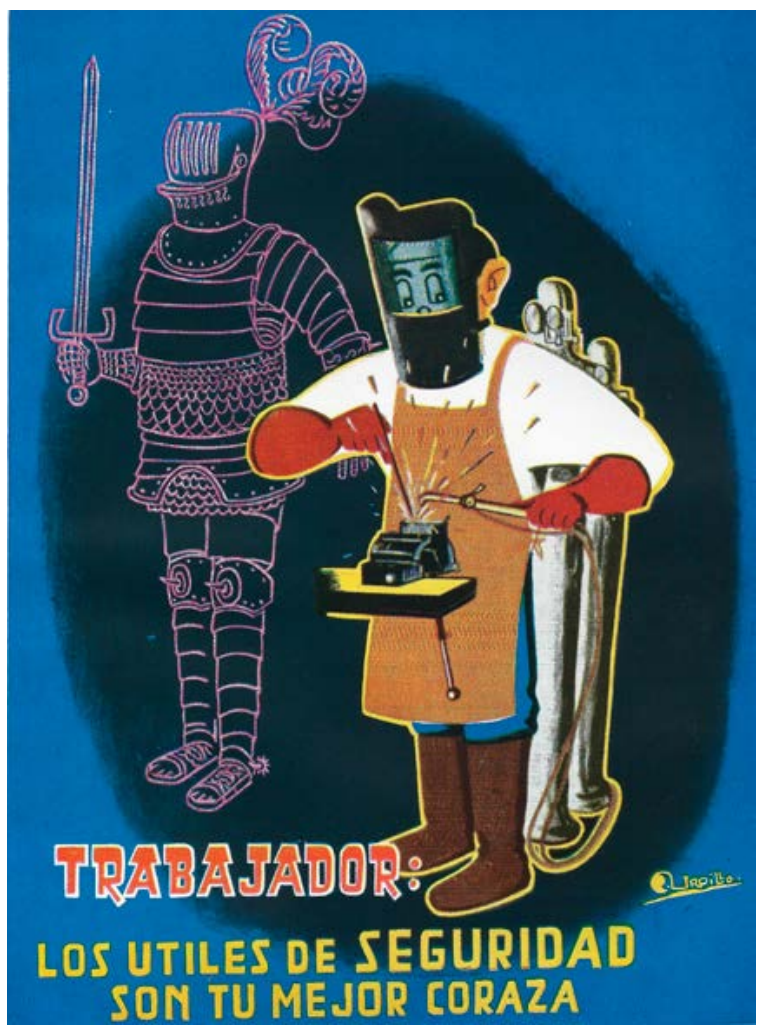

Imagen 4. Cartel premiado (primer premio) en el concurso convocado durante el III Congreso Nacional de Medicina y Seguridad en el Trabajo. Abril de 1957. Dibujado por el obrero Ramón Urdillo García, de la empresa Standard Eléctrica S.A. 


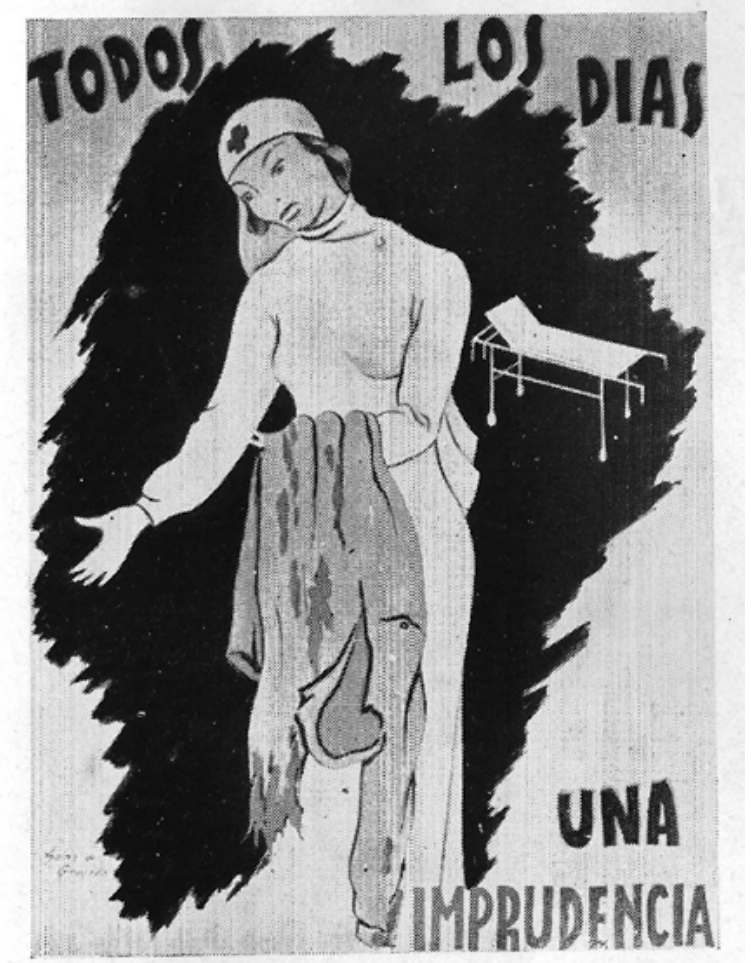

Imagen 5. Cartel premiado (segundo premio) en el concurso convocado durante el III Congreso Nacional de Medicina y Seguridad en el Trabajo. Abril de 1957. Dibujado por el obrero Fernando Sáinz Grajeda, de Forjas Alcalá de Henares.

tivo de confeccionar carteles para distribuir en los lugares de trabajo las oportunas consignas. Ejemplo de ello son los que convocaron el Instituto y el III Congreso Nacional de Medicina y Seguridad en el Trabajo ${ }^{23}$. En este último, se hizo una doble convocatoria: para artistas profesionales y para obreros. Dos de los cuatro carteles que fueron premiados en esta última categoría sirven de testimonio de cómo los obreros habían interiorizado la idea de que el trabajador, con sus distracciones y su falta de cumplimiento de las normas de seguridad, tenía responsabilidad en la producción de accidentes (Imágenes 4, 5) ${ }^{24}$.

\subsection{DIFUSIÓN RADIOFÓNICA: DANDO LA PALABRA A LOS AFECTADOS}

Un último contenido de la "educación sanitaria" que se realizó en el período analizado que nos interesa poner de relieve es el relacionado con la contribución que los propios afectados podían hacer a esa tarea. Una muestra es el compromiso que la Asociación Nacional de Inválidos Civiles, creada en 1958, ${ }^{25}$, iba a adquirir con la labor divulgativa de los nuevos planteamientos del gobierno y de los técnicos en relación con la discapacidad. De hecho, su participación estaba vinculada a una demanda que puede ser considerada una temprana expresión de uno de los lemas más relevantes -"nothing about us without us" ${ }^{26}$ que, desde la década de los años 90 se han sostenido en el marco del activismo por los derechos civiles de las personas con discapacidades. Tal como defendía Fernando Tamés Seminario ${ }^{27}$, presidente de la asociación, "todos los planes que se tracen, y todas las soluciones que se pretendan poner en práctica, darán mucho mejor resultado si se cuenta con los propios inválidos" (Tamés Seminario, 1963, p. 46).

Una muestra de la aportación de las propias personas con discapacidad la encontramos en el marco de una serie de intervenciones radiofónicas que Radio Nacional dedicó en 1963 "al problema de los disminuidos físicos y su rehabilitación". En una de ellas, Fernando Tamés transmitía la idea de que "los llamados inválidos son personas como las demás, en quienes la Providencia ha permitido que se den determinadas limitaciones que, en principio, les dificulta el desenvolvimiento de las actividades normales de la vida ordinaria". Se trasladaba así a la sociedad una imagen de las personas portadoras de deficiencias en la que se ponía el acento en la necesidad de considerarlas como individuos que, a pesar de poseer unas características determinadas, no debían ser considerados "seres distintos" ni tratados "como meros objetos de conmiseración o de una caridad limosnera". Era por ello legítimo reivindicar que les fueran facilitados "la máxima recuperación, tanto física y psíquica, como profesional" y "un puesto adecuado, en el conjunto social, con todos los derechos y deberes" (Tamés Seminario, 1963, p. 44).

De este modo, aunque se realizaba una demanda de actuaciones encaminadas a la rehabilitación de las personas discapacitadas, se hacía hincapié en la necesidad de que éstas unieran, a los derechos que se les reconocía, un compromiso con los deberes que también se estimaba que tenían con respecto a la sociedad. En este sentido, aunque en la tarea encaminada a acomodar las actitudes de los españoles ante la discapacidad se incorporaba de un modo significativo a los afectados, el modo en que expresaban sus reivindicaciones se ajustaba a la valoración que el régimen franquista realizaba de la discapacidad. En efecto, Tamés, en una lectura próxima a lo expresado en el Fuero del Trabajo, no dejaba de resaltar que la labor que se 
proponía para facilitar la recuperación de los “incapacitados" debía llevarse a cabo porque suponía "una obra de justicia, impuesta por la moral y postulados cristianos" y porque era "económicamente beneficiosa" para el Estado (Tamés Seminario, 1963, p. 44).

Hay que tener presente que la creación de la asociación había sido impulsa por el gobierno y que, aunque en teoría era un organismo autónomo, en realidad estaba sometida al control de las autoridades franquistas. De hecho, el nombramiento de su presidente nacional recaía en el Ministerio de la Gobernación. Este control se hacía patente también en la composición de su Junta nacional donde, junto a los Presidentes y los representantes del Consejo, estaban incluidos agentes del Régimen: dos asesores nacionales (eclesiástico y sindical) y representantes de la Dirección General de Empleo, de la Dirección General de Beneficencia y Obras Sociales, del Patronato de Rehabilitación y Recuperación de Inválidos, y del Patronato de Educación Especial ${ }^{28}$.

Cabe destacar, no obstante, que Tamés incorporaba en su discurso divulgador un argumento escasamente utilizado en el discurso "oficial". En un cierto tono de advertencia se dirigía a los radioyentes "capacitados" señalando que la rehabilitación debía ser apoyada, aunque fuera de una manera "inteligentemente egoísta”, por todos ellos. Su argumento era contundente y amenazador: "fácilmente se comprende que cualquier persona puede convertirse en inválido en el minuto más impensado" (Tamés Seminario, 1963, p. 44). En el marco de la educación sanitaria, España contó así con un antecedente de la forma con que los modernos activistas por los derechos de las personas discapacitadas han tratado de llamar la atención de la sociedad hacia su situación, y de concienciar acerca de ella a quienes se consideran como "normales". Para ello, de un modo no carente de ironía, se han dirigido a estos últimos denominándolos bajo el apelativo de "personas temporalmente capacitadas"29.

\section{EPÍLOGO: LOS LÍMITES DE LA “EDUCACIÓN SANITARIA", O CUANDO LA REHABILITACIÓN NO ES POSIBLE O ES INSUFICIENTE}

El régimen franquista consideró la discapacidad como un fenómeno portador de elementos negativos para el desarrollo del "Nuevo Estado". Las personas con deficiencias fueron contempladas como una oportunidad para aplicar esa caridad cristiana tan cara al Nacionalcatolicismo, pero también como un lastre para el desa- rrollo económico de la nación. La rehabilitación fue percibida en ese contexto como una vía para tratar de resolver el problema que la discapacidad representaba $y$, por ello, sus planteamientos fueron valorados favorablemente por las autoridades franquistas. Parecía oportuno apoyar la puesta en marcha de actuaciones como las que, con los médicos a la cabeza, se realizaban desde esa disciplina para convertir a personas discapacitadas en productores. Además de mejorar la riqueza, dichas medidas servían para contribuir a ejercer el control social (Martínez-Pérez y Del Cura, 2015; Martínez-Pérez, 2017). Ello pasaba por persuadir a la población de sus beneficios y de ganar su compromiso con las actuaciones que los técnicos encargados de llevar a cabo el programa rehabilitador -médicos, fisioterapeutas, maestros, terapeutas ocupacionales, psicólogos...- proponían. Con sus recursos y sus medios -prensa, folletos, charlas en la radio...- se trasladó a la población un conjunto de ideas que proporcionaban una imagen nueva de las personas discapacitadas. La más relevante de ellas fue la de que la rehabilitación poseía la capacidad de aproximar a las personas portadoras de deficiencias a la "normalidad" corporal y de conseguir su reeducación para posibilitar que pudieran desempeñar un trabajo ajustado a sus condiciones físicas y mentales. Se ponía así de relieve que personas consideradas como "inválidas" podían convertirse en personas productivas siempre y cuando, eso sí, siguieran las consignas de los expertos encargados de llevar a cabo su rehabilitación. Puede decirse que la propaganda y la educación sanitaria formaron parte de lo que se ha denominado "dispositivo de la discapacidad"; es decir de la presencia en la España franquista de una red de instituciones, espacios físicos, decisiones reglamentarias o legislativas, medidas administrativas, enunciados científicos, propuestas filosóficas y morales constituidas alrededor del concepto de discapacidad, (Cayuela, 2017, pp. 129-135), cuyo principal objetivo sería regular y tornar en espacio de actividad productiva, social y de conocimiento este fenómeno (Cayuela y Martínez-Pérez, 2018).

Una consecuencia de lo anterior, que los divulgadores de la rehabilitación se encargaron de poner de manifiesto, era que, dada esa capacidad de la disciplina para transformar a las personas consideradas "inválidas" en productores, era su deber someterse al proceso de rehabilitación y seguir adecuadamente las prescripciones que les indicaran los expertos. Este hecho conllevaba dos consecuencias negativas para las personas discapacitadas que no cumplieran con esa obligación. De un lado, en el plano económico, existía la posibilidad de que vieran recortada o reti- 
rada incluso la prestación que en forma de pensión les era concedida para ayudarles en su manutención. De otro, en el plano de su imagen social, su rechazo a seguir las intervenciones destinadas a su reeducación podía interpretarse como un signo de que se negaban a tratar de participar en la actividad productiva y, por tanto, se negaban a cumplir con ese deber superior que para el régimen franquista representaba el trabajo.

Junto a ello, la educación sanitaria en torno a la rehabilitación incorporaba otra consigna cuyo alcance iba más allá de las propias personas consideradas "incapacitadas" y cuya amenaza se extendía a todos los ciudadanos. La propaganda hacía hincapié en que la discapacidad se podía prevenir, especialmente en el caso de la siniestralidad laboral. El "factor humano", el trabajador, con su comportamiento negligente e irresponsable frente a la adopción de las medidas de seguridad, era considerado en muchos casos como el origen de los accidentes que acababan transformándolo en "inválido". De este modo, se trasladaba a la sociedad una idea poco positiva de las personas que quedaban con secuelas físicas y mentales tras un episodio de siniestralidad laboral: la de que podían ser responsables de su nueva situación por haber fracasado en su obligación de cumplir con las medidas preventivas.

Por otra parte, la educación sanitaria iba a facilitar el desarrollo dentro de nuestras fronteras de dos elementos que pueden ser interpretados favorablemente para las personas discapacitadas. A través de sus actuaciones se empezó a trasladar una idea más positiva de sus posibilidades de integración social. Se hizo un esfuerzo por modificar la terminología referida a ellas, planteando la conveniencia de sustituir la palabra "inválido" por "incapacitado", y se demandó una mayor y más decidida intervención legislativa e inversión económica del Estado para conseguir incrementar las posibilidades de mejorar la readaptación. Por otra parte, a través de la labor educativa se puso de manifiesto la incipiente participación que las propias personas afectadas demandaban en el proceso de toma de decisiones acerca de los asuntos que les concernían.

Conviene indicar que el alcance de esta labor divulgativa se hallaba muy afectado por las posibilidades reales que existían de llevar a cabo el programa que las autoridades trataban de impulsar. Oñorbe parecía consciente de ello cuando en 1963 afirmaba que se estaba "iniciando la organización de la asistencia sanitaria de la rehabilitación", pues se contaba con una red institucional "muy incompleta y concen- trada en limitado número de poblaciones" y se carecía de personal especializado (Oñorbe Garbayo, 1963, pp. 22-23). Aunque reconocía que se estaban dando pasos encaminados a superar la insensibilidad e indiferencia que "la gran masa de la población" mantenía hacia la rehabilitación, confiaba en que esa "momentánea incomprensión" supusiera sólo un pequeño retraso en la solución del problema de la discapacidad y que los resultados de la rehabilitación se observaran en un plazo de tiempo no muy lejano (Oñorbe Garbayo, 1963, p. 27)

La esperanza manifestada por Oñorbe, y compartida por otros impulsores de la rehabilitación, se iba a ver, no obstante, un tanto defraudada. A pesar de actuaciones importantes, como la que representó el Plan de operaciones para la rehabilitación ESPAÑA-23 -creado para mejorar la asistencia a los niños discapacitados mediante un acuerdo de colaboración firmado a finales de 1960 y principios de 1961 entre el Gobierno Español, la OMS y el Fondo de Naciones Unidas para la Infancia-, el alcance de las medidas fue muy limitado (Toledo Marhuenda y Ballester Añón, 2015). Factores como el retraso de los hospitales en adecuar espacios, la escasa capacidad para formar personal y para implantar puestos de trabajo en el sistema sanitario y los insuficientes recursos económicos destinados a la compra de material se han señalado como efectos principales de la escasa capacidad organizativa del gobierno y la incompetencia de sus dirigentes políticos para hacer efectivas las reformas propuestas. Como hemos señalado en otro lugar (Martínez-Pérez y Del Cura, 2015, pp. 818-822), en la década de los 60 se alzaron voces que ponían de manifiesto las dificultades para llevar a cabo la tarea rehabilitadora. Se denunciaba cómo el esfuerzo que se realizaba en las instituciones por parte del personal asistencial y de las personas acogidas para ser "rehabilitadas", no encontraba la recompensa, a veces simplemente por los prejuicios existentes hacia ellos, del acceso al trabajo. La España de esos años no estaba aún preparada para acometer el programa integrador que se transmitía a través de la educación sanitaria y hubo que esperar hasta la década de los 70 para superar esta coyuntura.

\section{AGRADECIMIENTOS.}

Este trabajo ha sido realizado en el marco del proyecto HAR2015-64150-C2-2-P, subvencionado por el Ministerio de Economía y Competitividad. 


\section{NOTAS}

1. Decreto de 9 de marzo de 1938. Boletín Oficial del Estado (B.O.E., en adelante), 10 marzo 1938.

2. Orden de 31 de enero de 1940, B.O.E. 3 febrero 1940.

3. Decreto de 8 de octubre de 1932, Gaceta de Madrid 12 octubre 1932. Este decreto sería conocido como la Ley de accidentes del trabajo de 8 de octubre de 1932.

4. Decreto de 6 de junio de 1949, B.O.E. 20 julio 1949.

5. Sobre el desarrollo de la rehabilitación y la fisioterapia en España véase Climent, 2001; Aguila Maturana, 2000 y Toledo Marhuenda, 2013.

6. Decreto de 28 de junio de 1957, B.O.E. 13 julio 1957.

7. I Symposium Médico-Social en el I.N.P. Tema de estudio: Rehabilitación del presunto inválido y Seguridad Social, Madrid, I.N.P., 1959.

8. Sobre el uso de la propaganda en la España franquista pueden verse Barrachina (1998) y Molinero (2005).

9. Perdiguero-Gil (2015) ha puesto de relieve cómo las actuaciones realizadas en los años veinte y treinta dirigidas a transformar las conductas de la población para acomodarlas a los dictados de los profesionales sanitarios se encuadraron bajo el término "propaganda". Bajo el influjo de tendencias procedentes del exterior fue creciendo la noción de "educación sanitaria popular", si bien, durante el período que exploramos "propaganda sanitaria" y "educación sanitaria” coexistieron.

10. La labor realizada en el siglo XX en España por los médicos para trasladar a la población no experta el conocimiento científico ha recibido una considerable atención historiográfica, que ha permitido poner de relieve su papel como elemento destinado a modificar las conductas e impulsar la hegemonía de los profesionales sanitarios en relación con el mantenimiento de la salud y el tratamiento de la enfermedad. Véase: Bernabéu-Mestre (1994); Jiménez Lucena, Ruiz Somavilla, y Castellanos Guerrero (2002); Rodríguez Ocaña y Molero Mesa (2005); Castejón, Perdiguero y Ballester (2006); Perdiguero, Ballester, y Castejón (2007a); Perdiguero, Ballester y Castejón (2007b); Rodríguez Ocaña, Perdiguero (2006); Perdiguero-Gil (2017).

11. De esta serie de folletos se han ocupado Josep Maria Comelles, Susan M. DiGiacomo y Enrique Perdiguero en una comunicación presentada a la 11th European Social Science History Conference y titulada "The weakness of health education in the Francoist Health System" (Valencia 30 de marzo-2 abril de 2016)

12. Una breve biografía de este médico se recoge en Freire Campo (1999).

13. Agradecemos al doctor Perdiguero Gil que nos haya facilitado el folleto del doctor Oñorbe.

14. Decreto de 13 de abril de 1961. B.O.E. 30 mayo 1961.

15. "Sevilla, sede del IV Congreso Nacional de la Sociedad Española de Rehabilitación. Declaraciones del doctor Oñorbe Garbayo", ABC (edición Sevilla), 2 de febrero de 1963, p. 27.
16. Algunas ideas sobre rehabilitación de inválidos, Madrid, Patronato Nacional de Rehabilitación de Inválidos, Dirección General de Sanidad, 1963.

17. Orden de 31 de enero de 1940. B.O.E. 3 febrero 1940.

18. Congreso Nacional de Medicina y Seguridad del Trabajo Bilbao, Agosto 1943, Madrid: Ministerio de Trabajo, 1944.

19. Decreto de 7 de julio de 1944. B.O.E. 26 julio 1944.

20. "El Instituto al servicio de las empresas y del obrero", Medicina y Seguridad del Trabajo. Revista del Instituto Nacional de Medicina y Seguridad del Trabajo, 1 (1), 1952, pp. 84-89, p. 86-87.

21. "Servicios Generales de Divulgación”, Medicina y Seguridad del Trabajo. Revista del Instituto Nacional de Medicina y Seguridad del Trabajo, 1 (4), 1953, pp. 65-71, p. 67.

22. "In memoriam. El doctor D. José Vidaurreta Aparicio", Medicina y Seguridad en el Trabajo. Revista del Instituto Nacional de Medicina y Seguridad del Trabajo, 2 (8), 1953, pp. 84-85.

23. "Concurso nacional de carteles de seguridad organizados por el Instituto", Medicina y Seguridad del Trabajo. Revista del Instituto Nacional de Medicina y Seguridad del Trabajo, 1 (1), 1952, pp. 90-91.

24. Crónica y actas del III Congreso Nacional de Medicina y Seguridad del Trabajo. Madrid, 8-13 abril 1957, Madrid, Nuevas Gráficas, s.a., 1957.

25. Orden de 29 de noviembre de 1958, B.O.E. 22 diciembre 1958. Sobre la gestación de la asociación puede verse Brégain (2013) y Martos Contreras (2017). Sobre los inicios del movimiento asociativo de personas con discapacidad puede verse Rodríguez Sánchez (2012) y Del Cura y Martínez-Pérez (2016).

26. Esa expresión -nada sobre nosotros, sin nosotros- aparecía en el título de un libro de James Charlton (1998, p.3), quien señalaba que la había oído "por primera vez en Sudáfrica en 1993" en boca de "dos líderes de Disabled People South Africa": Michael Masutha and William Rowland. Ambos referían que lo habían escuchado utilizar "por alguien de la Europa Oriental en una conferencia internacional sobre discapacidad y derecho".

27. Tamés era un abogado de origen vasco con una deficiencia motora. Dirigió la asociación y fue su imagen pública desde 1959 hasta su muerte en 1972. Una somera biografía suya apareció en la prensa con motivo de su fallecimiento: "Falleció en Madrid don Fernando Tamés Seminario", ABC (edición Madrid), 24 de noviembre de 1972, p. 43.

28. Orden de 14 de diciembre de 1959, B.O.E. 24 diciembre 1959.

29. El uso del término temporarily able bodied (TAB) para expresar que cualquiera puede cruzar la frontera que demarca la condición de "capacitado" y adquirir la etiqueta de "discapacitado" se ha hecho ubicuo en el discurso sobre la discapacidad. Ann Rae (1989) ha atribuido a Judy Heumann, fundadora del Work Institute on Disability, la introducción del término en Inglaterra. 


\section{BIBLIOGRAFÍA}

Águila Maturana, Ana María (2000), El debate médico en torno a la rehabilitación en España (1949-1969), Tesis doctoral, Madrid, Universidad Complutense.

Bachiller Baeza, Ángel (1985), La Medicina Social en España (el Instituto de Reeducación y la Clinica del Trabajo, 19221937), Valladolid, Universidad de Valladolid.

Ballester, Rosa (2012), "Los organismos sanitarios internacionales y la rehabilitación de los niños con discapacidades físicas (1948-1975)", Revista Estudios do Seculo XX, 12, pp. 89-101.

Barrachina, Marie-Aline (1998), Propagande et culture dans I'Espagne franquiste, 1939-1945, Grenoble, ELLUG Université Stendhal.

Bernabéu-Mestre, Josep (1994), "El Papel de la Escuela Nacional de Sanidad en el desarrollo de la Salud Pública en España", Revista de Sanidad de Higiene Pública, 68, pp. 65-89.

Bosch Marín, Juan (1959), "Conferencia del Dr. Bosch Marín”. En: I Symposium Médico-Social en el I.N.P. Tema de estudio: Rehabilitación del presunto inválido y Seguridad Social, Madrid, I.N.P., pp. 19-46.

Bravo, Julio (1951), Algunas consideraciones sobre la propaganda en general y propaganda sanitaria en particular, Madrid, Ministerio de la Gobernación-Dirección General de Sanidad.

Bravo, J. (1959), "Aspectos administrativos y sociales de la rehabilitación". En: I Symposium Médico-Social en el I.N.P. Tema de estudio: Rehabilitación del presunto inválido y Seguridad Social, Madrid, I.N.P., pp. 299-304.

Brégain, Gildas (2018), Pour une histoire du hándicap au XXe siècle. Approches transnationales (Europe et Ameriques), Rennes, Presses Universitaires de Rennes.

Brégain, Gildas (2013) "'Nous ne demandons pas la charité. Nous voulons du travail!'. La politique franquiste d'assistance aux invalides", Alter. European Journal of Disability Research, 7, pp. 206-221.

Castejón, Ramón; Perdiguero, Enrique; Ballester, Rosa (2006), "Los medios de comunicación al servicio de la lucha antivenérea y la protección de la salud materno-infantil (19001950)", História, Ciencias, Saûde - Manguinhos, 13 (2), pp. 411-437.

Cayuela Sánchez, Salvador (2017), “Hacia una biopolítica de las discapacidades. La cristalización de un dispositivo en el seno de la gubernamentalidad neoliberal", Eikasia. Revista de Filosofía, 75, pp. 113-138.

Cayuela, Salvador; Martínez-Pérez, José (2018), “El dispositivo de la discapacidad en la España del tardofranquismo (19591975): una propuesta de análisis", Asclepio, 70 (2): p232, doi: https://doi.org/10.3989/asclepio.2018.16

Charlton, James (1998), Nothing about us without us: Disability oppression and empowerment, Berkeley, University of California Press.
Climent Barberá, José María (2001), Historia de la rehabilitación médica: de la física terapéutica a la rehabilitación, Barcelona, Edika-Med.

Del Cura, Mercedes; Martínez-Pérez, José (2016), “From Resignation to Non-Conformism: Association Movement, Family and Intellectual Disability in Franco's Spain (1957-1975)", Asclepio, 68 (2), p149, doi: https://doi.org/10.3989/ asclepio.2016.21

Freire Campo, Jose Manuel (1999), "Manuel Oñorbe, médico", El País, 12 de febrero.

González Sánchez, José Juan (1997), Seguridad e higiene en el trabajo. Formación histórica y fundamentos, Madrid, Consejo Económico y Social.

Jiménez Lucena, Isabel; Ruiz Somavilla, María José; Castellanos Guerrero, Jesús (2002), "Un discurso sanitario para un proyecto político: La educación sanitaria en los medios de comunicación de masas durante el primer franquismo", Asclepio, 54 (1), pp. 201-218.

Lamas, F (1959), "La sesión inaugural. Palabras del Dr. Lamas". En: I Symposium Médico-Social en el I.N.P. Tema de estudio: Rehabilitación del presunto inválido y Seguridad Social, Madrid, I.N.P., pp. 13-18.

López Fernández, A; Bataller Sallé, J (1959), “Importancia de la rehabilitación en los planes de la Seguridad Social". En: I Symposium Médico-Social en el I.N.P. Tema de estudio: Rehabilitación del presunto inválido y Seguridad Social, Madrid, I.N.P., pp. 305-309.

Martínez-Pérez, José (1994), “La Organización Científica del Trabajo y las estrategias médicas de salud laboral en España (1922-1936)", Dynamis, 14, pp. 131-158.

Martínez-Pérez, José (1997), "Moldeando el estilo de vida del trabajador: la educación para la higiene y seguridad laboral en España (1922-1936)". En: Montiel, Luis; Porras, María Isabel (eds.), De la responsabilidad individual a la culpabilización de la víctima. El papel del paciente en la prevención de la enfermedad, Aranjuez, Doce Calles, pp. 125-133.

Martínez-Pérez, José (2001), "Medicina del Trabajo y prevención de la siniestralidad laboral en España (1922-1936)". En: Atenza, Juan; Martínez-Pérez, José (eds.), El Centro Secundario de Higiene de Talavera de la Reina y la Sanidad Española de su tiempo, Toledo, Junta de Comunidades de Castilla-La Mancha, pp. 235-255.

Martínez-Pérez, José (2006a), “El obrero recuperado: Medicina del Trabajo, Ortopedia y el impacto de la tecnología médica sobre la imagen social de las personas con discapacidades (España, 1922-1936)", História, Ciencias, Saúde - Manguinhos, 13 , pp. 349-373.

Martínez-Pérez, José (2006b), “Una nueva tecnología contra la siniestralidad laboral: innovación, Medicina y accidentes del trabajo en España (1920-1936)". En: Pérez-Bustamante, J.A. et al. (eds.), Actas del IX Congreso de la Sociedad Española de Historia de las Ciencias y de las Técnicas (2 vols), vol. I, Cádiz, SEHCYT, pp. 337-360. 
Martínez-Pérez, José (2009), “Consolidando el modelo médico de discapacidad: sobre la poliomielitis y la constitución de la Traumatología y Ortopedia como especialidad en España (1930-1950)", Asclepio, 61 (1), pp. 117-142.

Martínez-Pérez, José (2017), "Work, Disability and Social Control: Occupational medicine and Political Intervention in Franco's Spain (1938-1965)", Disability Studies Quaterly, 37 (4), doi: http://dx.doi.org/10.18061/dsq.v37i4.6098.

Martínez-Pérez, José; Porras Gallo, María Isabel (2006), “Hacia una nueva percepción de las personas con discapacidades: legislación, medicina y los inválidos del trabajo en España (1900-1936)", Dynamis, 26, pp. 195-219

Martínez-Pérez, José; Del Cura, Mercedes (2013), “Work injuries, scientific management, and the production of disabled bodies in Spain (1920-36)". En: Barsch, Sebastian; Klein, Anne; Verstraete, Pieter (eds.), The imperfect historian. Disability histories in Europe, Frankfurt am Main, Peter Lang, pp. 191-211.

Martínez-Pérez, José; Del Cura, Mercedes (2015), “Bolstering the Greatness of the Homeland: Productivity, Disability and Medicine in Franco's Spain, 1938-1966", Social History of Medicine, 28 (4), pp. 805-824.

Martos Contreras, Emilia (2017), “Trabajo y "minusvalía” durante el primer franquismo: la Asociación Nacional de Inválidos Civiles". En: González, Damián; Ortiz, Manuel; Pérez, Juan Sisinio (eds.) La Historia: lost in translation? Actas del XIII Congreso de la Asociación de Historiadores Contemporáneos, pp. 2787-2795.

Menéndez-Navarro, Alfredo (2015), The art of preventive health and safety in Europe, Bruselas, European Trade Institute.

Molinero, Carme (2005), La captación de las masas. Política social y propaganda en el régimen franquista, Madrid, Cátedra.

Oltra, Benjamín; De Miguel, Armando (1978), “Bonapartismo y Catolicismo. Una hipótesis sobre los orígenes ideológicos del Franquismo", Papers: Revista de Sociología, 8, pp. 53-102.

Oñorbe Garbayo, M (1963), Invalidez y Rehabilitación, Madrid, Servicio de Rehabilitación Sanitaria de la Dirección General de Sanidad-Ministerio de la Gobernación.

Palacios, Julián (1990), "La institución pionera de la Rehabilitación en España", Boletín del Real Patronato de Prevención y Atención a Personas con Minusvalía", 15, pp. 1-34.

Perdiguero Gil, Enrique; Castejón Bolea, Ramón (2012), “Introducción”. En: Castejón, Ramón; Perdiguero Enrique; Piqueras, José Luis (eds.), Las imágenes de la salud: cartelismo sanitario en España (1910-1950), Alicante, Instituto Alicantino de Cultura Juan Gil-Albert y Consejo Superior de Investigaciones Científicas, pp. 9-22.

Perdiguero, Enrique; Ballester, Rosa; Castejón, Ramón (2007a), "La propaganda sanitaria en la II República: la Sección de Higiene Social y Propaganda de la Dirección General de Sanidad". En: Campos, Ricardo; Montiel, Luis; Huertas, Rafael (eds.), Medicina, Ideología e Historia en España (siglos $X V I-X X I)$, Madrid, Consejo Superior de Investigaciones Científicas, pp. 303-316.
Perdiguero, Enrique; Ballester, Rosa; Castejón, Ramón (2007b), "Films in Spanish Health Education: The Case of Child Health (1928)-1936)”, Higyea Internationalis, 6 (2), pp. 69-97.

Perdiguero-Gil, Enrique (2015), “La 'educación sanitaria' en el ideario médico-social del franquismo a través de la revista SER". En: Perdiguero-Gil, Enrique (ed.), Política, salud y enfermedad en España: entre el desarrollismo y la transición democrática, Alicante, Universidad Miguel Hernández de Elche. Libro digital: https://editorial.edu.umh.es/2015/12/09/ politica-salud-y-enfermedad-en-espana-entre-el-desarrollismo-y-la-transicion-democratica/

Perdiguero-Gil, Enrique (2017), “La popularización médica durante el franquismo: un primer acercamiento". En: Comelles, Josep Maria; Perdiguero Gil, Enrique (coords.), Educación, comunicación y salud, Tarragona, URV, pp. 105-138.

Piga, A. (1959), "Bases y proyecto de un servicio de rehabilitación y valoración de lesionados en el Instituto Nacional de Medicina y Seguridad del Trabajo". En: I Symposium Médico-Social en el I.N.P. Tema de estudio: Rehabilitación del presunto inválido y Seguridad Social, Madrid, I.N.P., pp. 317-324.

Rae, Ann (1989), "What's in a Name?" International Rehabilitation Review, 8. Disponible en: University of Leeds Centre for Disability Studies Research Archive: https://disabilitystudies.leeds.ac.uk/wp-content/uploads/sites/40/library/ Rae-Whatsname.pdf [Fecha de consulta: 25-04-2018]

Rodríguez Ocaña, Esteban; Molero Mesa, Jorge (2005), “La cruzada por la salud. Las campañas sanitarias del primer tercio del siglo $\mathrm{XX}$ en la construcción de la cultura de la salud". En: Montiel, Luis (coord.), La salud en el Estado de Bienestar (Análisis histórico), Madrid, Editorial Complutense, pp. 133-148.

Rodríguez Ocaña, Esteban; Perdiguero, Enrique (2006), “Ciencia y persuasión social en la medicalización de la infancia en España, siglos XIX-XX", História, Ciencias, Saûde - Manguinhos, 13 (2), pp. 303-324.

Rodríguez Sánchez, Juan Antonio (2012), "Las secuelas sociales de la polio: los inicios del movimiento asociativo en España (1957-1975)", Dynamis, 32 (2), pp. 391-414.

Ruiz Carnicer, Miguel Ángel (2004), “La educación popular en el régimen franquista”. En: Gracia, Jordi; Ruiz Carnicer, Miguel Ángel, (eds.), La España de Franco (1939-1975). Cultura y vida cotidiana, Madrid, Editorial Síntesis, pp. 69-125.

Safford, Frank. K.; Hanson, Kurt (1957), Programa Nacional de rehabilitación de niños físicamente disminuidos (Informe de una misión en España), Madrid, Ministerio de la Gobernación-Dirección General de Sanidad.

Sanchis-Olmos, V. (1959), "Rehabilitación del presunto inválido y Seguridad Social". En: I Symposium Médico-Social en el I.N.P. Tema de estudio: Rehabilitación del presunto inválido y Seguridad Social, Madrid, I.N.P., pp. 325-328.

Tamés Seminario, Fernando (1963), "La Asociación Nacional de Inválidos. Sus problemas, sus inquietudes, sus aspiraciones". En: Charlas radiofónicas. El problema de los disminuidos físicos y su rehabilitación, Madrid, Patronato de Rehabilita- 
ción de Inválidos-Ministerio de la Gobernación-Dirección General de Sanidad, pp. 41-48.

Toledo Marhuenda, José Vicente (2013), La poliomielitis en España (1880-1970) y su impacto sobre el desarrollo de las técnicas en fisioterapia: un acercamiento a la historia de las discapacidades físicas y a su tratamiento, Elche, Universidad Miguel Hernández de Elche.

Toledo Marhuenda, José Vicente; Ballester Añón, Rosa (2015), "Los intentos de rehabilitación del régimen franquista y los consejos de expertos internacionales para la rehabilitación y tratamiento fisioterápico de niños con discapacidades físicas (1960-1975)". En: Perdiguero-Gil, Enrique (ed.), Politica, salud y enfermedad en España: entre el desarrollismo y la transición democrática, Alicante, Universidad Miguel Hernández de Elche.

Vega Díaz, F (1959), "Cardiopatías en la Medicina del Trabajo. Rehabilitación del enfermo cardiovascular". En: I Symposium Médico-Social en el I.N.P. Tema de estudio: Rehabilitación del presunto inválido y Seguridad Social, Madrid, I.N.P., pp. 81-110. 